\title{
Muscular blood oxygen level-dependent MRI is beneficial to evaluate effectiveness of an exercise prescription
}

\author{
Yilong Huang ${ }^{1 \#}$, Jialu Wei ${ }^{2 \#}$, Dan Han ${ }^{1}$, Yuanming Jiang ${ }^{1}$, Jia Zhang ${ }^{1}$, Zhenguang Zhang ${ }^{1}$, Bo He ${ }^{1}$ \\ ${ }^{1}$ Department of Medical Imaging, the First Affiliated Hospital of Kunming Medical University, Kunming, China; ${ }^{2}$ Department of Radiology, The \\ 3rd People's Hospital of Kunming, Kunming, China \\ Contributions: (I) Conception and design: Y Huang, Z Zhang, B He; (II) Administrative support: B He; (III) Provision of study materials or patients: \\ J Wei, Z Zhang; (IV) Collection and assembly of data: Y Huang, J Wei, Y Jiang, J Zhang, D Han; (V) Data analysis and interpretation: Y Huang, J \\ Wei, B He; (VI) Manuscript writing: All authors; (VII) Final approval of manuscript: All authors. \\ \#These authors contributed equally to this work. \\ Correspondence to: Bo He. Medical Imaging Department, First Affiliated Hospital of Kunming Medical University, Kunming, China. \\ Email: hebo_ydyy@qq.com; Zhenguang Zhang. Medical Imaging Department, First Affiliated Hospital of Kunming Medical University, Kunming, \\ China. Email: 178546941@qq.com.
}

Background: To determine the feasibility and validity of using blood oxygen level-dependent (BOLD) magnetic resonance imaging (MRI) to evaluate the effects of back extension exercise on core lumbar paraspinal muscle strength.

Methods: In this prospective study, R2* and T2 mapping of paraspinal muscles of 100 healthy volunteers were performed before and after back extension exercises in different recovery sessions (session I, II, III or IV). Volunteers use the Roman chair to complete the back extension exercises. The cross-sectional area (CSA), R2* and T2 values were measured and analyzed in 3 muscles (iliocostalis, longissimus, and multifidus muscles) of the lower back before and after exercise.

Results: The CSA and T2 values of iliocostalis, longissimus, and multifidus muscles at L3 and L4 levels were higher in recovery sessions I and II than in the resting-state $(\mathrm{P}<0.05)$; however, compared to that in the resting-state, the $\mathrm{R} 2$ * value was significantly reduced in session I but increased in sessions II-IV $(\mathrm{P}<0.05)$. Furthermore, the CSA and T2 values in recovery session I were higher than those in the resting-state, whereas the $\mathrm{R} 2$ * value was lower $(\mathrm{P}<0.05)$. After exercise, the recovery tendency of $\mathrm{R} 2$ * and $\mathrm{T} 2$ value was consistent in both males and females, but a significant sex difference in $\mathrm{R} 2$ * value was observed between recovery sessions III and $\mathrm{IV}(\mathrm{P}<0.05)$.

Conclusions: R2* mapping and T2 mapping are effective and feasible for assessment of the effects of back extension exercises on lumbar paraspinal muscle strength.

Keywords: Blood oxygen level-dependent (BOLD); blood flow; excess post-exercise oxygen consumption; exercise prescription; core paraspinal muscle

Submitted Dec 23, 2020. Accepted for publication Mar 05, 2021.

doi: $10.21037 / \mathrm{atm}-21-279$

View this article at: http://dx.doi.org/10.21037/atm-21-279

\section{Introduction}

Regular and appropriate exercise improves health status (1), lowers the risk of chronic diseases (2), and strengthens muscular function (blood flow and oxygenation level) (3). Exercise training, such as back extension exercises, is often used to improve the strength and endurance of the core lumbar paraspinal muscles (namely, the multifidus, longissimus, and iliocostalis muscles), and can even prevent and treat pain in the lower back $(4,5)$.

Exercise prescriptions have many advantages for fitness, disorder prevention, and treatment $(1,2,4)$. The same Different people are suitable for different exercise 
Table 1 Baseline characteristics of the 100 volunteers

\begin{tabular}{lcccccc}
\hline Characteristics & Group 1 & Group 2 & Group 3 & Group 4 & $\chi^{2} / F$ & P \\
\hline Sex (males/females) & $12 / 13$ & $11 / 14$ & $12 / 13$ & $13 / 12$ & 0.321 & 0.956 \\
Age (year) & $23.64 \pm 1.73$ & $23.80 \pm 2.18$ & $24.52 \pm 2.18$ & $24.12 \pm 2.32$ & 0.845 & 0.473 \\
Height (cm) & $164.80 \pm 7.56$ & $165.76 \pm 7.92$ & $165.92 \pm 6.73$ & $166.92 \pm 7.09$ & 0.350 & 0.789 \\
Weight (kg) & $56.83 \pm 4.61$ & $57.78 \pm 6.93$ & $58.65 \pm 5.84$ & $59.47 \pm 6.39$ & 0.891 & 0.449 \\
BMI (kg/m ${ }^{2}$ ) & $20.93 \pm 1.22$ & $20.98 \pm 1.42$ & $21.27 \pm 1.27$ & $21.30 \pm 1.33$ & 0.544 & 0.654 \\
Heart rate (bmp) & $71.68 \pm 5.88$ & $70.28 \pm 5.63$ & $72.08 \pm 7.13$ & $71.00 \pm 5.29$ & 0.431 & 0.731 \\
Oxyhemoglobin saturation (\%) & $96.32 \pm 1.35$ & $96.16 \pm 1.55$ & $96.24 \pm 1.05$ & $96.40 \pm 1.19$ & 0.159 & 0.924 \\
\hline
\end{tabular}

The values of age, height, weight, BMI, heart rate, and oxyhemoglobin saturation are shown as mean \pm standard deviation. BMI, body mass index, was calculated as weight/height ${ }^{2}$.

prescription may bring different effects on everyone. The effectiveness of such prescriptions varies depending on the form, intensity, and duration of the exercise $(3,5,6)$. However, it is unclear whether an exercise prescription can be effective for a healthy individual and a patient undergoing rehabilitation $(7,8)$. Obviously, effective, fast, and accurate assessment of the effectiveness of exercising can be extremely helpful in optimizing exercise prescriptions for both healthy individuals and patients (9).

At present, the effects of exercise prescriptions are evaluated based on clinical outcomes (such as pain, blood sugar, blood lipids, and blood pressure), markers of energy metabolism (such as peak oxygen consumption and maximal voluntary contraction), and muscle cross-sectional area (CSA) or signal intensity by the T2WI (2,9-11). However, these indicators often reflect the long-term effects of exercise and cannot be applied to conduct timely modifications of exercise prescriptions. Furthermore, most of these indicators reflect the whole-body responses instead of local changes, such as blood variances in lumbar muscles.

Currently, blood oxygen level-dependent (BOLD) magnetic resonance imaging (MRI) is commonly employed for the assessment of brain neuronal activation $(12,13)$. The BOLD MRI signal is mainly dependent on the level of paramagnetic deoxyhemoglobin and can be used as a marker for the level of tissue oxygenation $(14,15)$. The ratio of deoxyhemoglobin to oxyhemoglobin in the blood can be reflected by the relaxation rate $(\mathrm{R} 2 *)$, which is expressed in units of Hz. R2* has a reciprocal relationship with $\mathrm{T} 2$ * (12-15). Studies have used R2* and T2 mapping to detect the biological metabolism of various diseases, such as fatty degeneration, muscular dystrophy, cartilage damage, and ischemic injury of skeletal muscle and myocardium (16-20).
Moreover, diabetic rodent studies have found that R2* can be used to evaluate visceral adipose tissue oxygenation status (21). Thus, it is worth investigating whether $\mathrm{R} 2^{*}$ and T2 mapping can be used to evaluate the effectiveness of exercise prescription effectiveness.

Therefore, this preliminary prospective study aimed to determine the sensitivity, feasibility, and validity of using R2* and T2 mapping, as well as CSA measurement, to evaluate the effects of a designed exercise prescription on 3 different paraspinal muscles (the iliocostalis, longissimus, and multifidus muscles) of young healthy volunteers in the resting state and different recovery sessions post exercise. We presented the following article in accordance with the MDAR reporting checklist (available at http://dx.doi. org/10.21037/atm-21-279).

\section{Methods}

\section{Volunteer selection}

This prospective study was approved by the ethics committee of local hospital. Through screening, we recruited 100 healthy volunteers from the First, Second and Third Affiliated Hospitals of Kunming Medical University in this study (48 males and 52 females). All volunteers have signed informed consent. The age ranges were 20-28 years, with an average age of $24.08 \pm 2.14$ years. Physiological baseline information is displayed in Table 1. The baseline values of all participants were strictly controlled to avoid the influence of factors other than exercise prescription on the volunteers' muscles. The results of the MR lumbar examination of all 100 volunteers were negative. None of the subjects reported lower back pain or presented with 


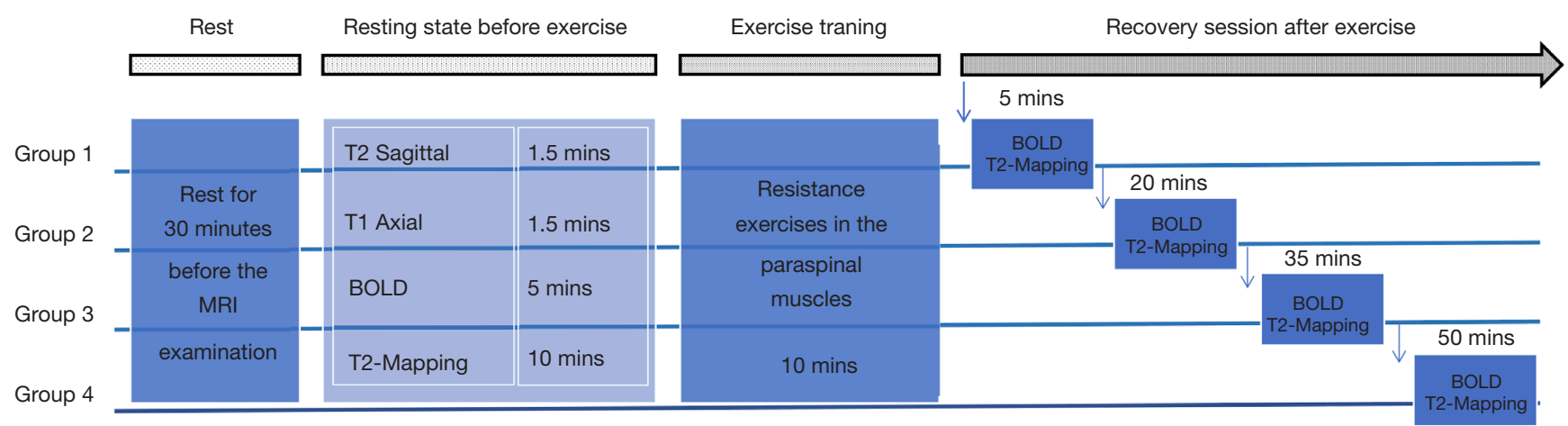

Figure 1 The MRI examination protocol for paraspinal muscle function. Including resting state before exercise (18 minutes), exercise training (10 minutes), and 4 recovery sessions in this study. BOLD and T2 mapping were performed before and after exercise (5 and 10 minutes, respectively). BOLD, blood oxygen level-dependent.

clinical signs of lumbar disk herniation. The exclusion criteria included: professional muscle training, lesions, history of lumbar spine surgery, paravertebral muscle atrophy, and all standard contraindications for MRI examination. This study was conducted in accordance with the Declaration of Helsinki (as revised in 2013).

\section{Study design and a protocol for back extension exercise}

All 100 volunteers rested for 30 minutes before performing a set of back extension exercises. To exclude subjects with lumbar disease, sagittal T2-weighted imaging of the general lumbar spine and axial T1-weighted imaging of lumbar discs were conducted prior to exercise. After the first acquisition of BOLD MRI R2* and T2 mapping data in the resting state, the back extension exercises were performed for 10 minutes outside the scanning room. A $45^{\circ}$ roman chair was chosen for the volunteers to perform the back extension exercise in this study. The back extension exercises were focused specifically on the lower back, and the height of the upper roman chair pad could be adjusted to allow enough room for the volunteers to bend their waist without any restrictions. The steps for the prescribed exercise were as follows (22): (I) cross the hands behind the head, keeping the body straight; (II) bend the waist slowly, keep the back straight; and (III) slowly raise the torso back to the initial position. All enrolled subjects repeated the aforementioned steps 45 times for each set of exercises. To ensure the intensity, duration, and form of exercise were consistent, the volunteers were coached and their movement supervised at all times by the same physician who specializes in sports medicine. $\mathrm{R} 2{ }^{*}$ and $\mathrm{T} 2$ mapping was acquired in the following time points after exercises: 5, 20, 35, and 50 minutes. According to the time points of the second scan, the 100 volunteers were equally and randomly divided into 4 groups ( 25 volunteers in each group): recovery I (5 min), Recovery II (20 min), Recovery III (35 min), and Recovery IV (50 min). And the same scanning protocol was used for all volunteers.

\section{MRI examination}

All MRI scans were conducted using a 3.0 T MR scanner (Achieva Tx, Philips, Netherlands). To reduce the adverse impact of respiratory motion artifacts during the MR examinations, the volunteers' abdomen was compressed with an abdominal bandage in the standard supine position.

The lower back was scanned twice for each volunteer with the examination protocol involving the sagittal T2WI of the lumbar spine, axial T1WI of the intervertebral discs, axial muscle BOLD MRI (R2*) images (Figure 1 ). R2* and T2 mapping images were computerized respectively via multi-echo fast field echo (mFFE) with fat suppression (repetition time $(\mathrm{TR})=466 \mathrm{~ms}$; echo time $(\mathrm{TE})=3.7,10.3$, $15.9,21.5,27.1,32.7 \mathrm{~ms}$; voxel $=1.5 \times 1.5 \times 3.0 \mathrm{~mm}^{3}$; slice thickness $=3.0 \mathrm{~mm}$; slice increment $=0.0 \mathrm{~mm}$; field of view $(\mathrm{FOV})=100 \times 218 \times 72 \mathrm{~mm}^{3}$; and number of excitation $(\mathrm{NEX})=6)$ and fast spin-echo (FSE) without fat suppression ( $\mathrm{TR}=1,974 \mathrm{~ms}$; $\mathrm{TE}=7,13,19,25,31$, and $37 \mathrm{~ms}$; voxel $=0.76 \times 0.76 \times 3.0 \mathrm{~mm}^{3}$; slice thickness $=3.0 \mathrm{~mm}$; slice increment $=0.7 \mathrm{~mm}$; FOV $=100 \times 211 \times 79 \mathrm{~mm}^{3}$; and NEX $=1$ ) by aligning the first slice parallel to the upper edge of L3 and the lower edge of L4 in all volunteers (Figure $2 A$ ). 

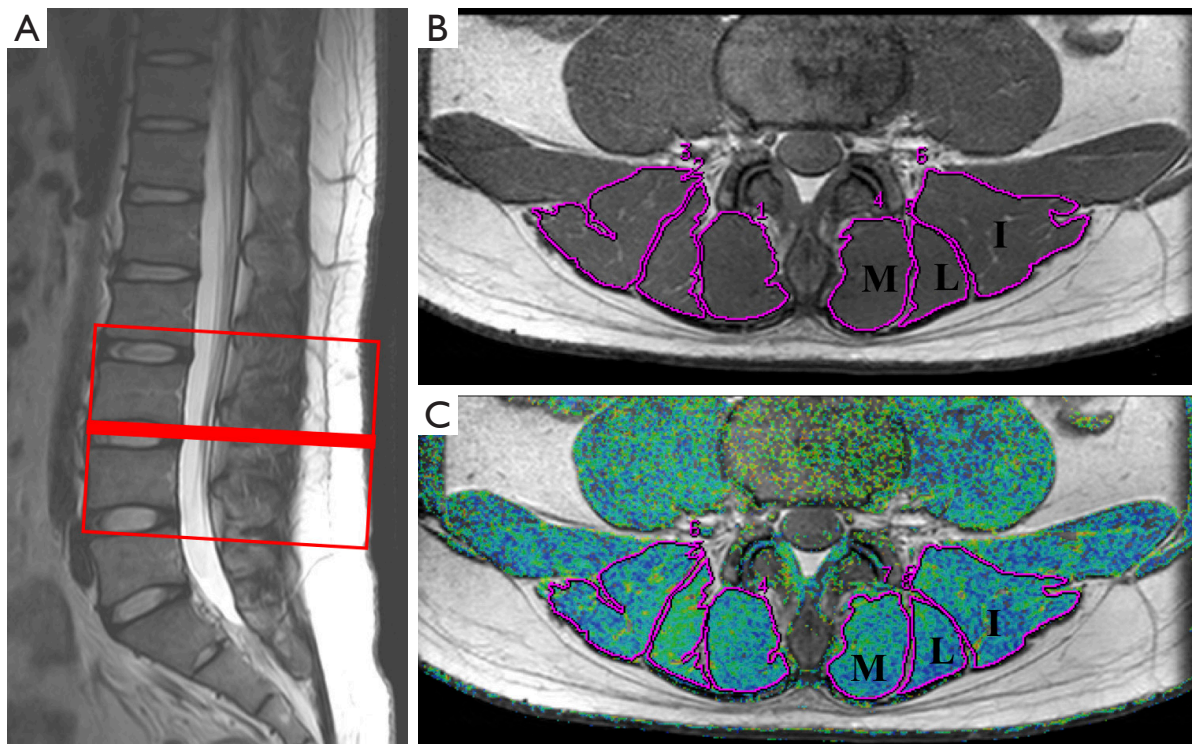

Figure 2 The scan of the spine and the delineation of muscles. (A) The central level of the scan is located on the upper edge of L4 in the T2-weighted sagittal images (thick red line). (B,C) The regions of interest in the upper edge of L3 and L4. I, iliocostalis; L, longissimus; M, multifidus.

\section{Data measurements and analysis}

The image series of each volunteer were analyzed independently on a commercially available workstation (AW 4.4, GE, USA) by two experienced radiologists in the department of musculoskeletal radiology. The exercise time and all identifying personal details (including name, age, and sex) were removed from the images to protect the privacy and identity of the volunteers. The radiologists were blinded to the volunteers' information and the imaging examination time. The CSA, R2*, and T2 values of the bilateral paravertebral muscles (iliocostalis, longissimus, and multifidus muscles) were measured based on the regions of interest (ROIs) on the superior and inferior margins of the L3 and L4 vertebral. The edge of the paravertebral muscles were manually delineated by two radiologists (Figure $2 A, B, C$ ). After the two radiologists had performed the measurements three times, the average quantitative values were calculated for analysis in order to increase the accuracy of measurement. The ROIs were placed to exclude the tendon and fat compositions in the muscles. The color range of the R2* images was $20-100$, and the color range of the T2 mapping images was 33-71.

There were 4 recovery sessions after exercise: 5, 20, 35 , and 50 minutes. According to the following equations, the $\mathrm{CSA}_{\text {total }}, \mathrm{R} 2{ }^{*}$ total, and $\mathrm{T} 2$ total values of the muscles were calculated, respectively:

$$
\begin{aligned}
& \mathrm{CSA}_{\text {total }}=\mathrm{CSA}_{\text {iliocostalis }}+\mathrm{CSA}_{\text {longissimus }}+\mathrm{CSA}_{\text {multifidus }} \\
& \mathrm{R} 2 *_{\text {total }}=\mathrm{R} 2 *_{\text {iliocostalis }}+\mathrm{R} 2 *_{\text {longissimus }}+\mathrm{R} 2{ }_{\text {multifidus }} \\
& \mathrm{T} 2_{\text {total }}=\mathrm{T} 2_{\text {iliocostalis }}+\mathrm{T} 2_{\text {longissimus }}+\mathrm{T} 2_{\text {multifidus }}
\end{aligned}
$$

\section{Statistical analysis}

SPSS 22.0 software was used for statistical analysis. Data were shown as mean \pm standard deviation. One-way analysis of variance (ANOVA) was used to compare differences in the CSA, $\mathrm{R} 2{ }^{*}$, and $\mathrm{T} 2$ values of the three paraspinal muscles between the resting state and each recovery session after exercise. The CSA, R2*, and T2 values were compared between males and females using the independent-samples $t$ test. A P value $<0.05$ was considered statistically significant.

\section{Results}

\section{Analysis of CSA, R2*, and T2 values between the resting state and each recovery session}

No significant differences were observed in the CSA, R2*, and $\mathrm{T} 2$ values among the 4 groups before exercise $(\mathrm{P}<0.05$; Table 2). Compared the CSA, R2*, and T2 values between the resting state and each recovery session, there were significant differences at the L3, L4, and L3-L4 levels of the 
Table 2 Comparison of CSA, R2*, and T2 values between the 4 groups before exercise

\begin{tabular}{lcccccc}
\hline Parameters & Group 1 & Group 2 & Group 3 & Group 4 & $F$ & P \\
\hline CSA $\left(\mathrm{mm}^{2}\right)$ & $6,133.09 \pm 1,374.65$ & $6,356.83 \pm 1,977.01$ & $6,311.92 \pm 1,219.09$ & $6,418.42 \pm 1,078.86$ & 0.186 & 0.905 \\
R2* value $(\mathrm{HZ})$ & $559.87 \pm 34.89$ & $571.05 \pm 43.85$ & $586.01 \pm 35.83$ & $571.62 \pm 83.26$ & 0.137 & 0.938 \\
2 value $(\mathrm{ms})$ & $611.78 \pm 54.02$ & $634.72 \pm 30.55$ & $608.54 \pm 48.55$ & $633.99 \pm 52.72$ & 0.551 & 0.650 \\
\hline
\end{tabular}

All values are mean \pm standard deviation. CSA, cross-sectional area.

A
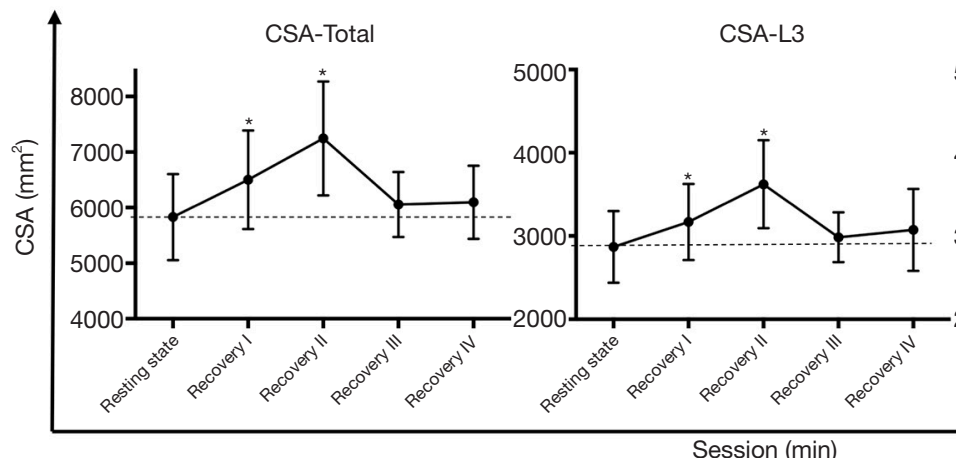

B

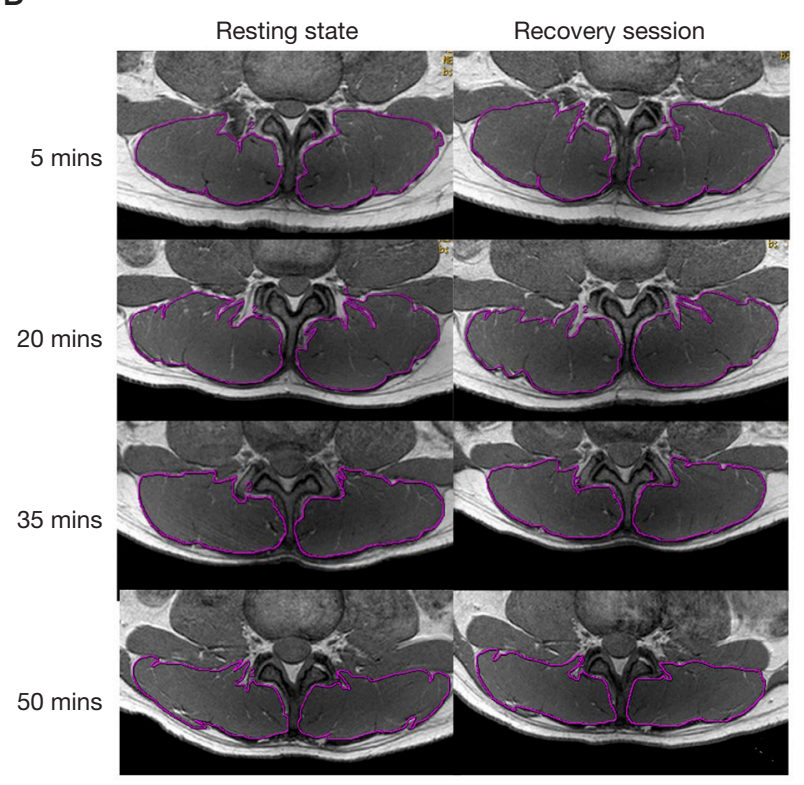

C
CSA-L4

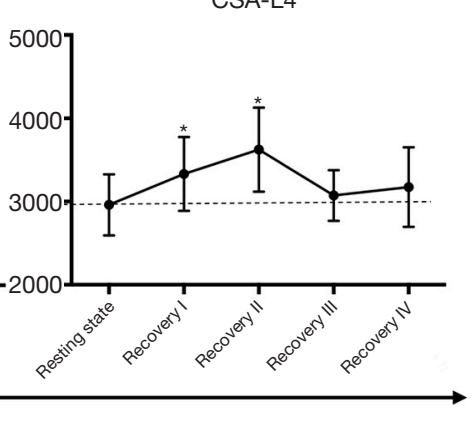

L4 Level

$$
\text { Resting state Recovery session }
$$

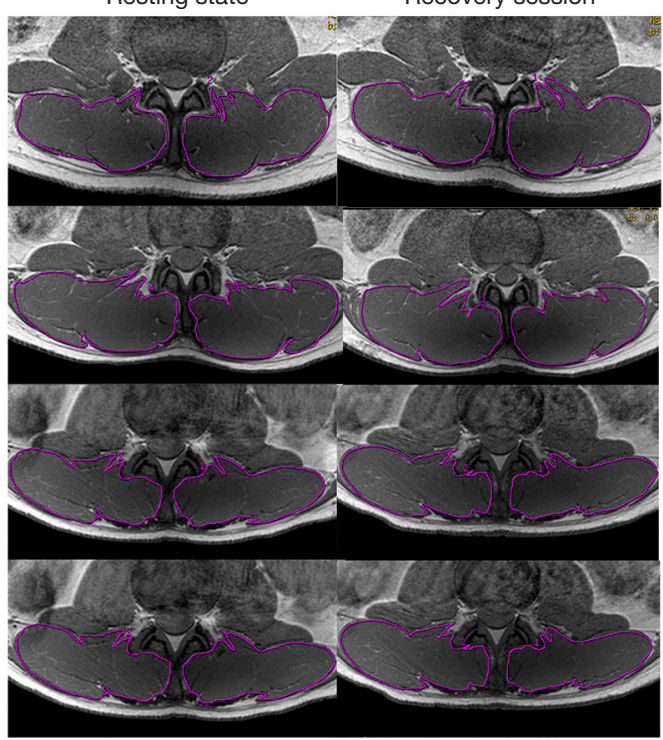

Figure 3 The differences in CSA between resting state and recovery sessions. Sample images of 4 recovery sessions from 4 different volunteers. (A) The line chart of CSAs in different recovery sessions. (B,C) Axial T2 maps were used to measure the CSA values of the paraspinal muscles at the upper edge of L3 and L4. ${ }^{*}$ Compared with resting state, $\mathrm{P}<0.05$.

iliocostalis, longissimus, and multifidus muscles (Figures 3-5 and Tables 3-5). The CSA values at the L3-L4 level of the 3 paravertebral muscles differed significantly between the resting state and recovery sessions I and II, respectively. The CSA at the L3 and L4 levels of all muscles was higher in recovery session II than in other sessions $(\mathrm{P}<0.05$; Figure $3 A, B, C)$. For all muscles, the CSA values at the $\mathrm{L} 3$ level, L4 level, and L3-L4 level were highest in recovery session II followed by recovery session I. All values in recovery sessions III and IV were low, as were those in 
A

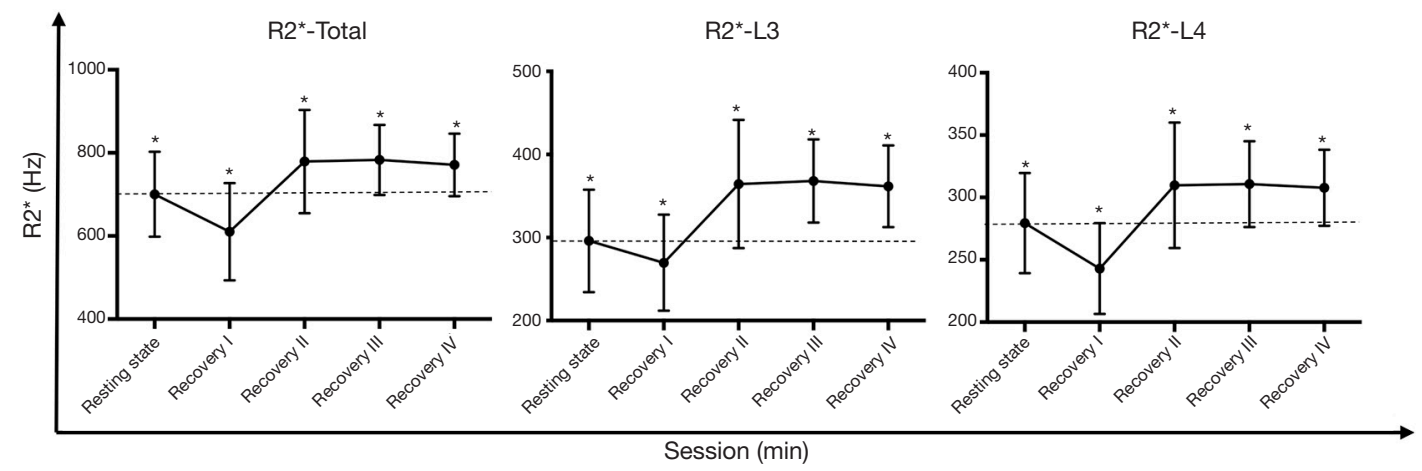

B

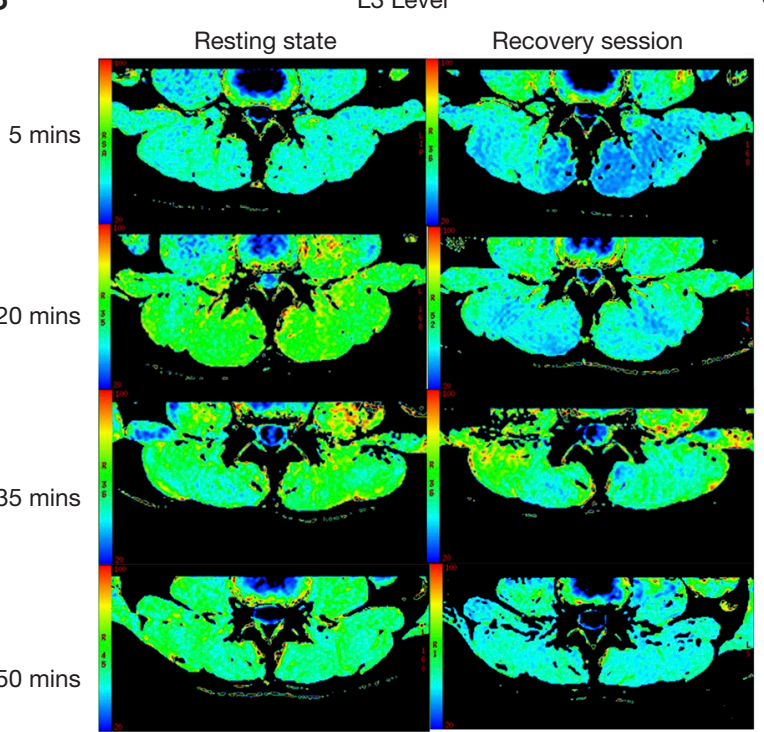

C Resting state L4 Level

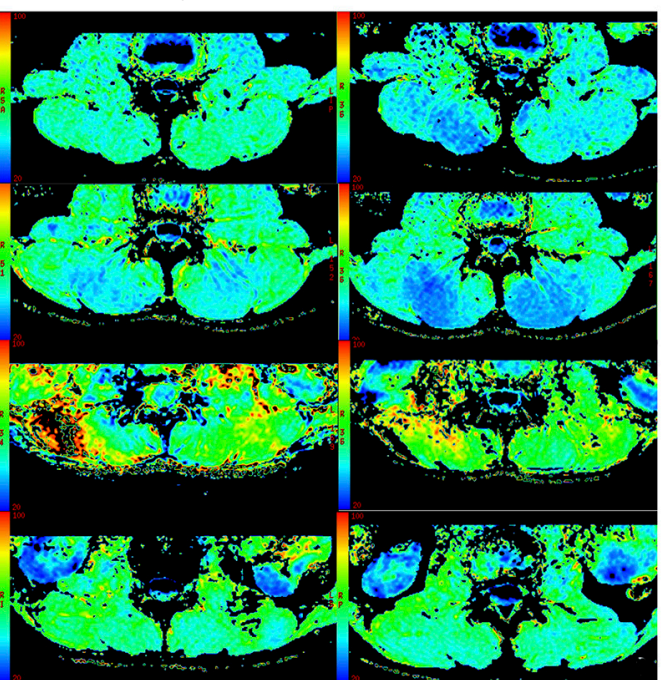

Figure 4 The differences in R2* value between resting state and recovery sessions. The same volunteers as in Figure 4 . (A) The line chart of the R2* values in different recovery sessions. (B,C) Color-coded R2* maps. R2* maps obtained before exercise and in 4 recovery sessions after exercise $\left(5,20,35\right.$, and 50 minutes) at L3 and L4. ${ }^{*}$ Compared with resting state, $\mathrm{P}<0.05$.

the resting state. The CSA values of the longissimus and multifidus muscles were higher in all recovery sessions than in the resting state $(\mathrm{P}<0.05$; Table 3). There were no significant differences in CSA at the L3 and L4 levels of the iliocostalis muscle $(\mathrm{P}>0.05$; Table 3$)$.

The $\mathrm{R} 2 *$ values in the resting state and recovery sessions were compared, and the differences at the L3 level, L4 level, and L3-L4 level were statistically significant for all measured lower back muscles ( $\mathrm{P}<0.05$; Figure 4 and Table 4$)$. The R2* value in recovery session I was lower than that in the resting state before exercise, whereas the $\mathrm{R} 2 *$ of all muscles at the L3, L4, and L3-L4 levels were statistically higher in recovery sessions II-IV than in the resting state $(\mathrm{P}<0.05)$.

The T2 values at the L3 level, L4 level, and L3-L4 level of all muscles were statistically higher in recovery sessions I and II than in the resting state $(\mathrm{P}<0.001$; Figure 5). Similarly, the T2 value at the L4 level was higher in the recovery sessions than the resting state, although the difference was not statistically significant $(\mathrm{P}>0.05)$. Furthermore, the $\mathrm{T} 2$ values at the 3 different paraspinal muscles significantly increased in the recovery sessions compared with the resting state $(\mathrm{P}<0.05$; Table 5$)$.

\section{Sex comparisons of CSA, R2*, and T2 values}

Overall, males tended to have a larger CSA in the 3 muscles pre and post exercise $(\mathrm{P}<0.001$; Figure 6). Sex comparisons of the CSA, R2*, and T2 values of the all muscles, as well as the total values of all 3 muscles, before and after exercise 
A

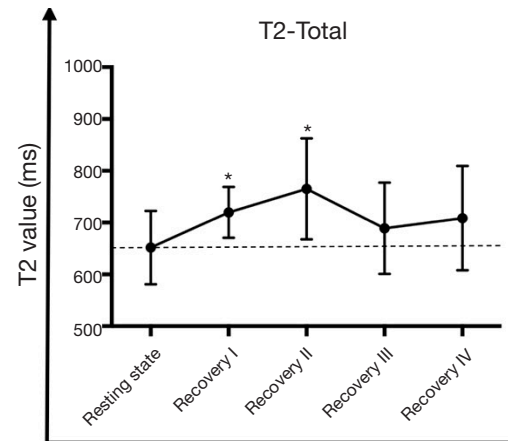

B

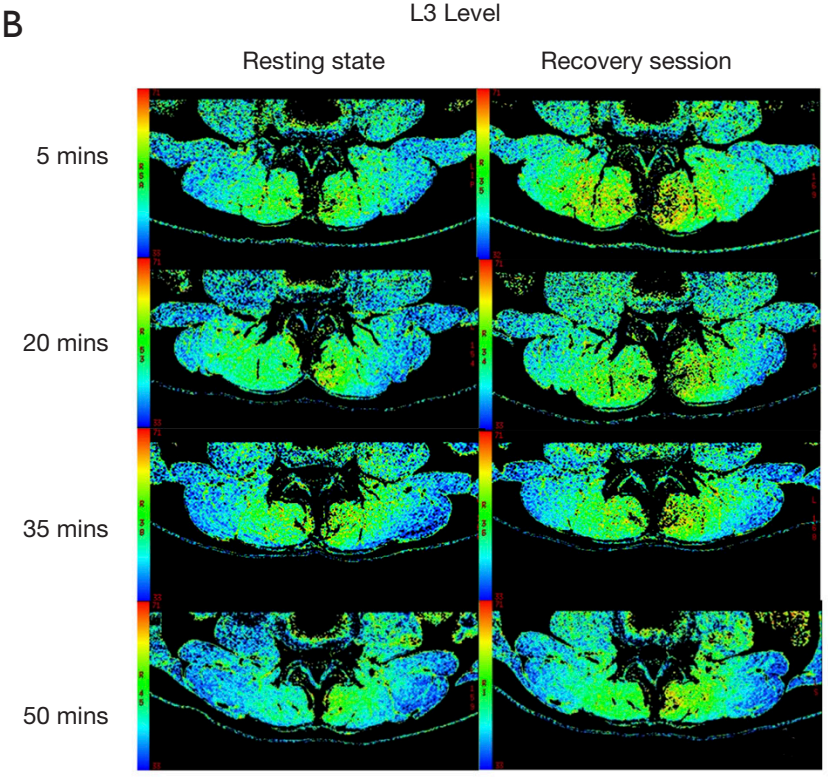

T2-L3

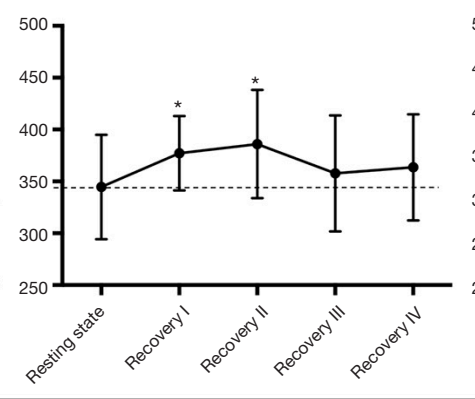

C
T2-L4

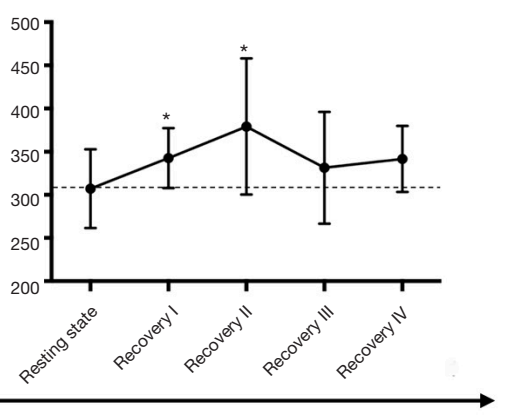

L4 Level

Resting state Recovery session

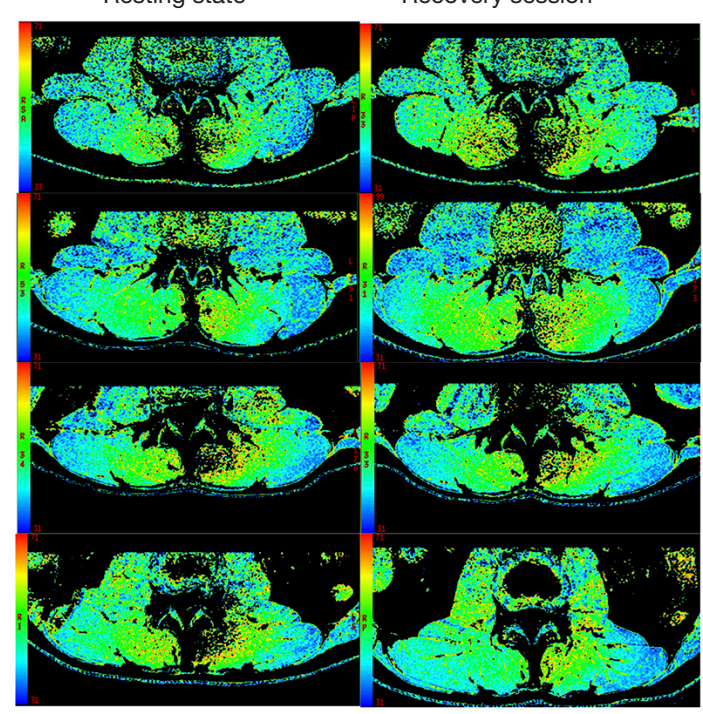

Figure 5 The differences in T2 values between resting state and recovery sessions. The same volunteers as in Figures 4 and 5. (A) The line chart of $\mathrm{T} 2$ values in different exercise sessions. (B) Color-coded T2-calculated map. T2 maps obtained pre exercise and in 4 recovery sessions after exercise (5, 20, 35, 50 minutes) after exercise at the L3 level. (C) T2 maps at the L4 level. *Compared with resting state, $\mathrm{P}<0.05$.

were carried out, and significant differences were found after exercise (Figures 6-8). In both males and females, the $\mathrm{CSA}$ and $\mathrm{T} 2$ values were higher and the $\mathrm{R} 2{ }^{*}$ value was lower in recovery session I than in the other sessions in all muscles $(\mathrm{P}<0.05)$. Regardless of sex, the values of all parameters for the 3 lower back muscles were highest in recovery session II.

A significant sex difference in $\mathrm{R} 2$ * value was observed between recovery sessions III and IV $(\mathrm{P}<0.05)$. After exercise, the recovery tendency of $\mathrm{R} 2$ * value was consistent in both males and females (Figure 7). Furthermore, except for those in recovery session I, the T2 values of the longissimus and multifidus muscles in the recovery sessions II-IV were higher in males than in females $(\mathrm{P}<0.05)$.
However, there was no difference in the $\mathrm{T} 2$ value of the iliocostalis muscle between males and females in the different sessions. In all recovery sessions, the $\mathrm{T} 2$ value showed the same tendency in both sexes (Figure 8).

\section{Discussion}

Our study demonstrated that R2* mapping and T2 mapping have potential utility for the evaluation of the effectiveness of back extension exercises in improving lumbar paraspinal muscle strength in healthy individuals. Morphological and functional differences pre and post exercise showed minutelevel changes in oxygenation concentration, which may have potential application value of dynamic observation of 
Table 3 CSA values of paraspinal muscles in the resting state and in different recovery sessions after exercise $\left(\mathrm{mm}^{2}\right)$

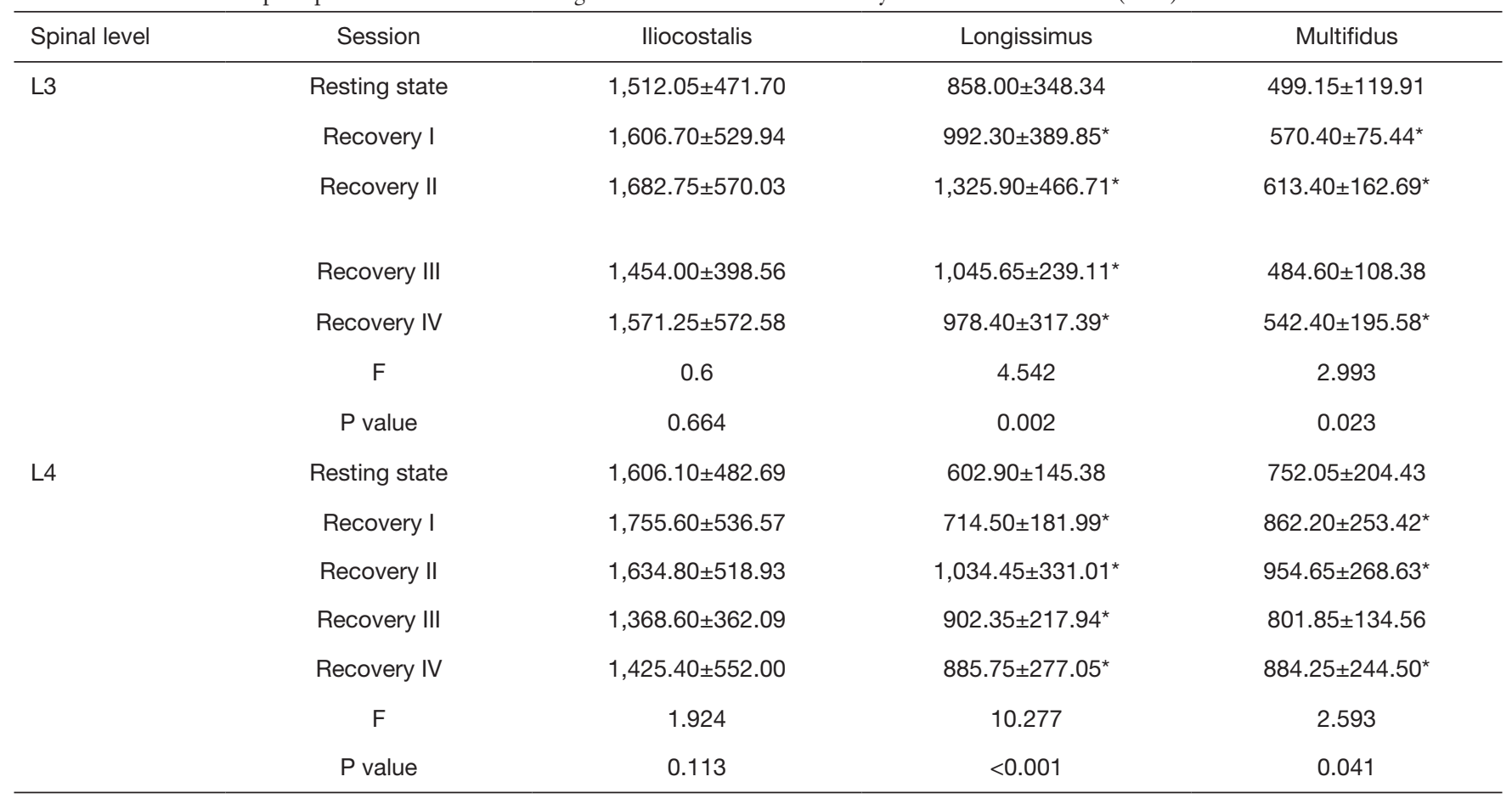

All values are mean \pm standard deviation. ${ }^{*}$ Compared with resting state, $\mathrm{P}<0.05$. CSA, cross-sectional area.

Table 4 R2* values of paraspinal muscles in the resting state and in different recovery sessions after exercise $(\mathrm{Hz})$

\begin{tabular}{|c|c|c|c|c|}
\hline Spinal level & Session & Iliocostalis & Longissimus & Multifidus \\
\hline \multirow{5}{*}{ L3 } & Recovery I & $93.26 \pm 21.72^{*}$ & $88.07 \pm 19.75^{\star}$ & $88.39 \pm 19.35^{\star}$ \\
\hline & Recovery II & $127.74 \pm 27.90^{*}$ & $115.49 \pm 24.84^{*}$ & $121.18 \pm 26.3^{*}$ \\
\hline & Recovery III & $125.80 \pm 22.53^{*}$ & $118.27 \pm 18.13^{*}$ & $120.99 \pm 14.65^{\star}$ \\
\hline & $\mathrm{F}$ & 13.933 & 18.166 & 18.191 \\
\hline & $P$ value & $<0.001$ & $<0.001$ & $<0.001$ \\
\hline \multirow[t]{5}{*}{ L4 } & Resting state & $92.98 \pm 14.62$ & $91.79 \pm 13.66^{*}$ & $94.64 \pm 15.02$ \\
\hline & Recovery I & $83.76 \pm 16.09^{\star}$ & $79.04 \pm 15.14^{*}$ & $80.17 \pm 17.15^{\star}$ \\
\hline & Recovery IV & $101.88 \pm 13.00^{*}$ & $101.36 \pm 12.64^{*}$ & $104.55 \pm 10.62^{*}$ \\
\hline & $\mathrm{F}$ & 18.691 & 16.485 & 21.475 \\
\hline & $P$ value & $<0.001$ & $<0.001$ & $<0.001$ \\
\hline
\end{tabular}

All values are mean \pm standard deviation. ${ }^{*}$ Compared with resting state, $\mathrm{P}<0.05$. 
Table 5 T2 values of paraspinal muscles in the resting state and in different recovery sessions after exercise (ms)

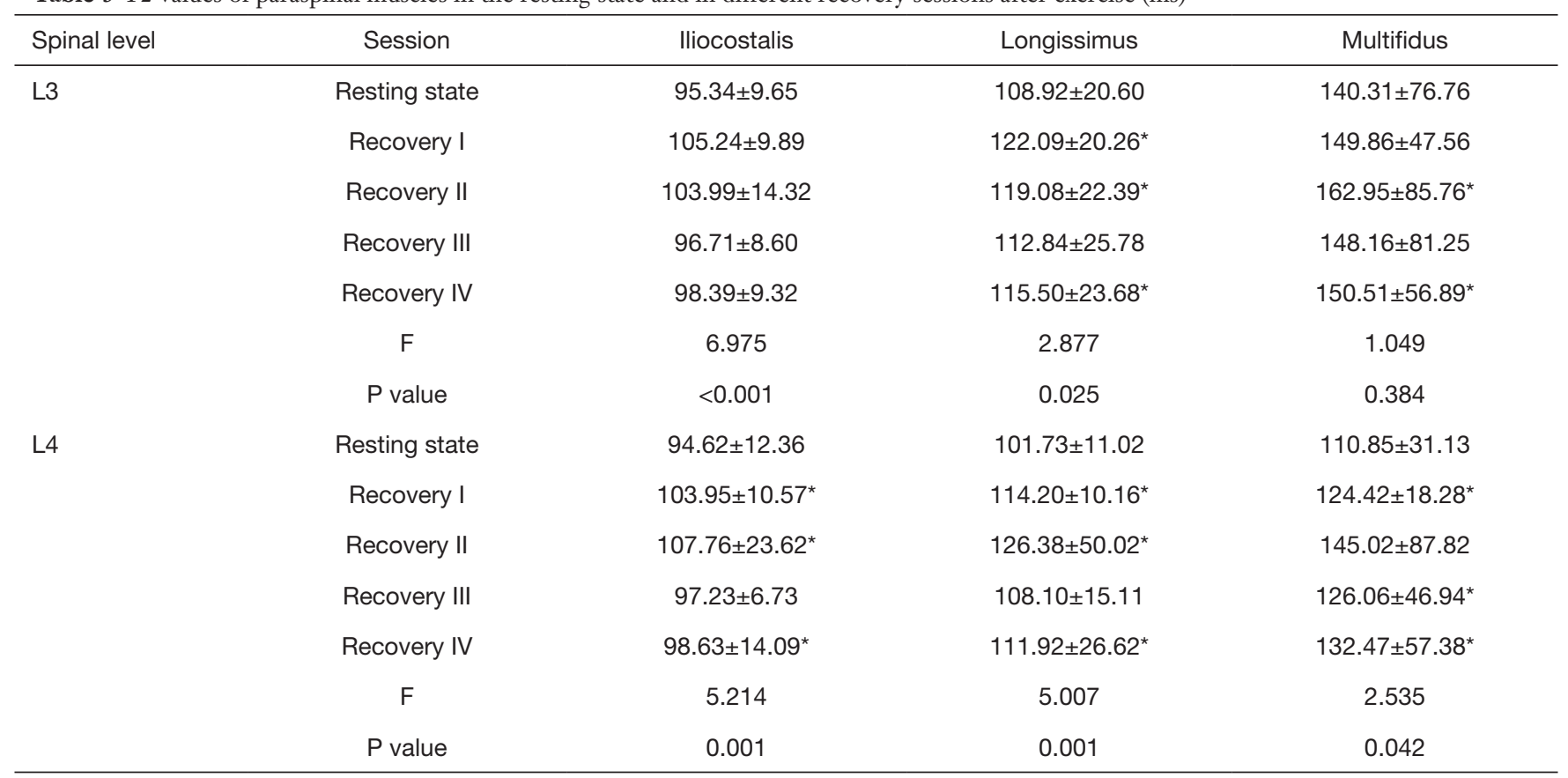

All values are mean \pm standard deviation. ${ }^{*}$ Compared with resting state, $\mathrm{P}<0.05$.

general muscle function and energy metabolism, especially the blood flow and oxygenation level of muscles.

BOLD MRI was initially introduced in the study of brain oxygenation level, blood flow, and biological metabolism (23), and few studies have applied BOLD MRI to skeletal muscle $(17,24,25)$. Compared to devices that record expiratory carbon dioxide concentrations as an indirect reflection of whole-body energy consumption and the blood oxygen level, BOLD MRI enables noninvasive mapping of blood oxygenation changes in regional muscle tissues $(13,17,20,24,25)$. Although BOLD MRI is limited by contraindications and medical expenses, it can evaluate the metabolism changes of deep muscle tissue in high-resolution anatomical images. The BOLD mainly depends on the content of paramagnetic deoxyhemoglobin, which indirectly measures the oxygenation level and microcirculation blood perfusion by detecting $\mathrm{R} 2^{*}$ changes.paramagnetic ss In our study, after back extension exercises, the $\mathrm{R} 2^{*}$ value changed from showing a rapid decline to a rapid rise, followed by a steadily flat trend in the recovery sessions, while remaining higher than the baseline of the resting state. Previous research has shown that blood flow in human muscles rapidly increases at the onset of exercise and then decreases to the baseline level (26). The rapid decrease in $\mathrm{R} 2 *$ value may explain the phenomenon of accelerated blood flow, increased intramuscular inflow, and the large amount of oxygenated hemoglobin after exercise. The increase in R2* value of sessions III-IV indicated a significant increase in oxygenated hemoglobin and even climbed over the baseline of the resting state. However, the pattern of changes in R2* value at 20 minutes after exercise was inconsistent with that of blood flow (27). This difference indicates that blood flow may not be a major factor affecting the signal during the post-exercise recovery phase.

Unexpectedly and surprisingly, R2* mapping may have reflected the excess post-exercise oxygen consumption (EPOC) effect (which refers to the amount of oxygen consumed after physical activity) in the lower back muscles of our volunteers. The human body burns more calories after exercise than during exercise, and oxygen consumption remains higher after exercise than before exercise, lasting for several hours (28). It has also been considered to be closely related to fat consumption $(29,30)$. The extra oxygen consumption after exercise appears to increase adipose oxidation and thus plays an important role in blasting fat (31). Furthermore, some studies have confirmed that the energy consumption mainly originates from fat oxidation during the post-exercise period $(32,33)$. The phenomenon of body temperature elevation and lactic acid clearance 
A

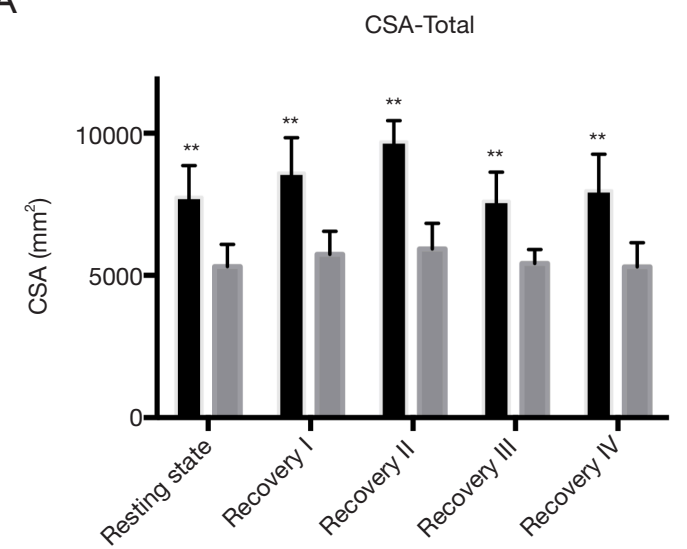

C

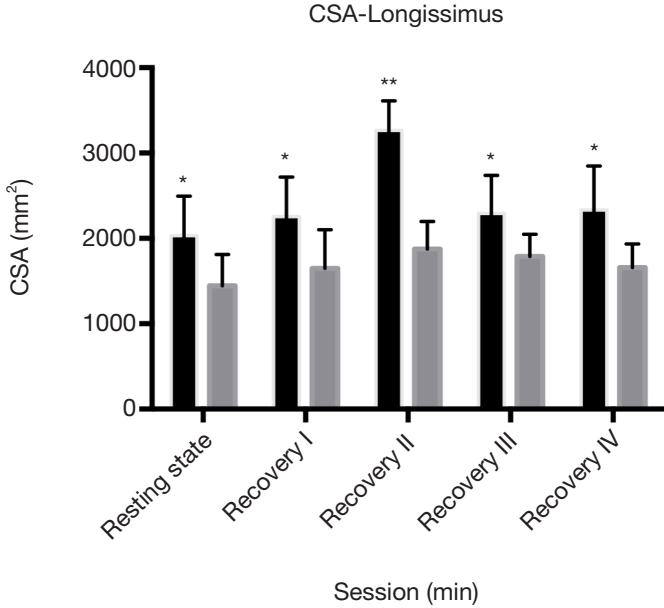

B

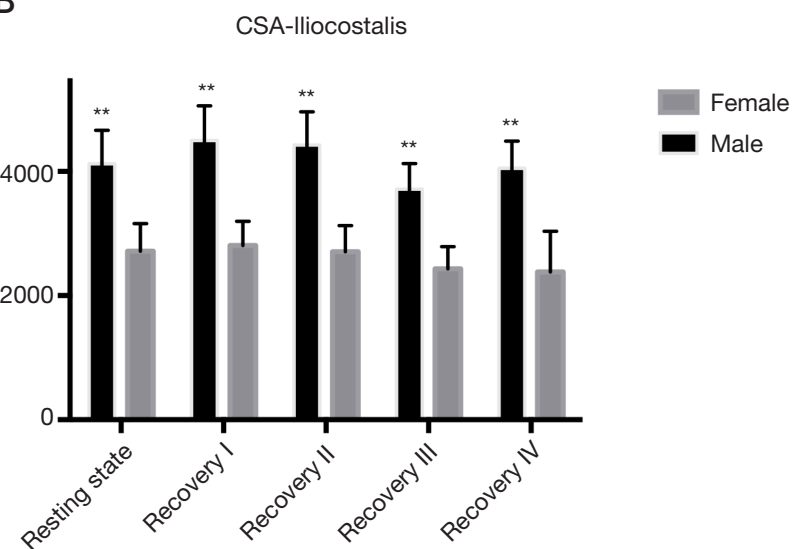

D

CSA-Multifidus

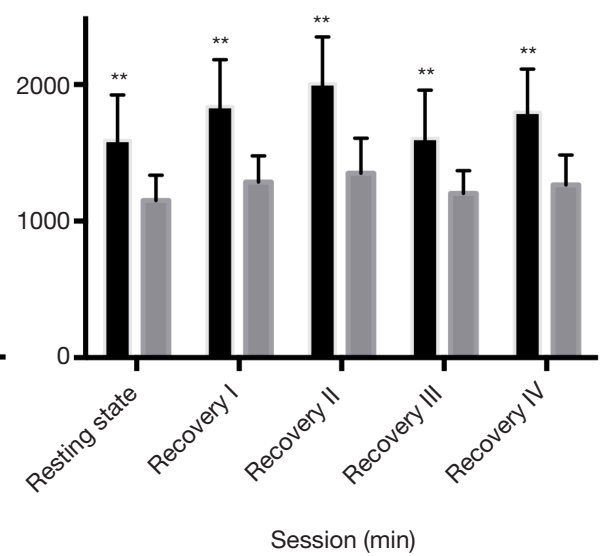

Figure 6 Sex differences in CSA of the three paraspinal muscles between resting state and recovery sessions. (A) The total value of 3 muscles; (B) iliocostalis; (C) longissimus; and (D) multifidus. ${ }^{*} \mathrm{P}<0.05$, ${ }^{* *} \mathrm{P}<0.01$. CSA, cross-sectional area.

after exercise leading to increased oxygen consumption in muscle tissues might be reflected via the $\mathrm{R} 2 *$ value in the recovery sessions (34), which would be consistent with the classical EPOC mechanism. Therefore, BOLD MRI may also be a potential tool for detecting EPOC in the future. In addition, previous studies have found that BOLD MRI could provide insight into visceral adipose tissue and thus could be used to evaluate its oxygenation status (35). The $\mathrm{R} 2$ * value, in reflection of the increasing concentration of deoxyhemoglobin, can reveal the severity of hypoxia (36). In the current study, the lower R2* values at 20 minutes after exercise compared to the baseline might reflect increased oxygen and energy consumption by hypoxic muscle and adipose tissues.

In our study, the CSA and T2 values of the paraspinal muscles increased slowly and then decreased rapidly after exercise, but remained higher in recovery session III than in the resting state. The T2 and CSA values were both decreased significantly at 35 minutes post exercise and were extremely close to the baseline of the resting state. These results indicated that changes in T2 and CSA values possibly reflected increased blood flow, as described by Schewzow et al. (37). Besides, it has been reported that the accumulation of lactic acid in muscle cells increases after skeletal muscle exercises, resulting in increased water content in the extracellular space $(38,39)$. In other words, much higher intramuscular inflow in the paraspinal muscles of males than those of females' might be reflected by T2 mapping. The exercise-related changes in the CSAs of males were also larger than those in females, while the variance patterns of both sexes were consistent. Therefore, there are sex-related physiological changes in the regional paraspinal muscles after back extension exercise, as described by Smith et al. (40).

The present study has some limitations. Firstly, R2* 
A

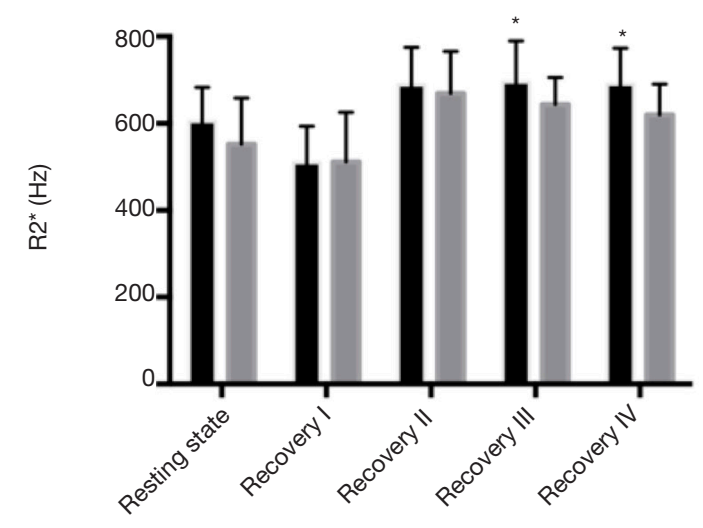

C

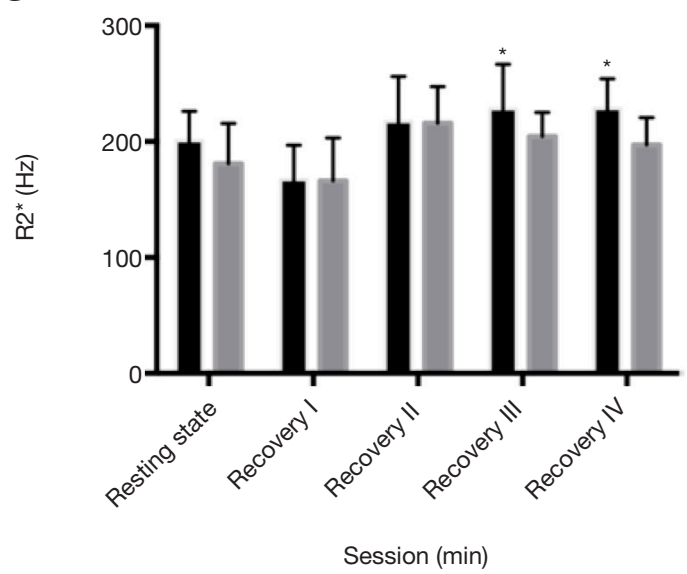

B

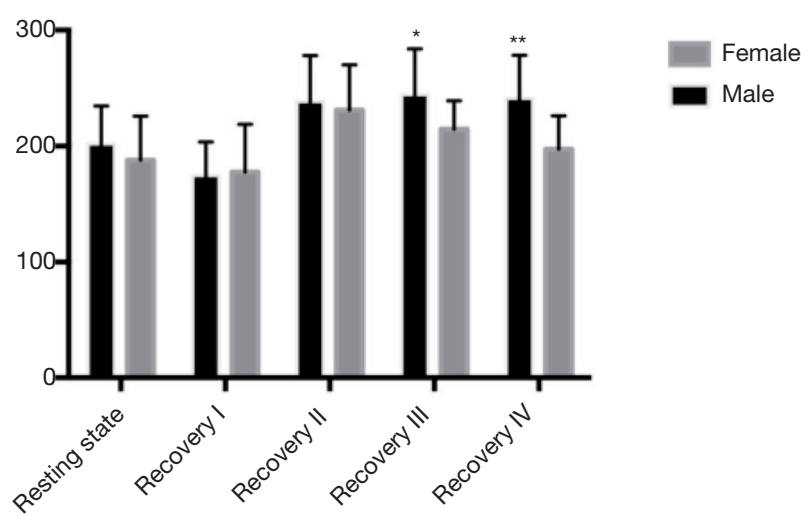

$\mathrm{R} 2{ }^{\star}$-Multifidus

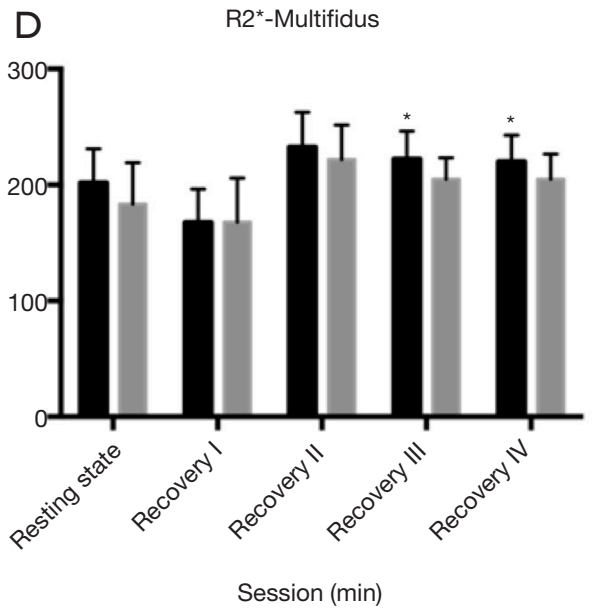

Figure 7 Sex differences in R2* of the 3 paraspinal muscles between resting state and recovery sessions. (A) The total value of 3 muscles; (B) iliocostalis; (C) longissimus; and (D) multifidus. ${ }^{*} \mathrm{P}<0.05,{ }^{* *} \mathrm{P}<0.01$.

and T2 mapping could not keep track of BOLD changes during back extension exercises. No random scanning order was applied in our study to avoid sequential accumulation or an inverse effect. For instance, BOLD MR imaging is always performed first and then T2 imaging. Secondly, 5 consecutive acquisitions of R2*- and T2-weighted images took a long time and caused a thermal effect. In order to eliminate group bias, each study participant underwent MR examination, once pre-exercise and once during a randomly assigned recovery session. Thirdly, the specific exercise prescription is suitable for specific people. On the basis of normal volunteers, further research on patients can be more feasible to utilize the application of BOLD MRI and may assist clinicians to observe treatment effects and prognostic diagnosis. Therefore, patients with low back pain will be recruited and performed BOLD MRI in the future.
Customized modifications of the exercise prescription may be fulfilled through exploring the changes in CSA and MRI functional markers before and after exercise.

In conclusion, this study has demonstrated that BOLD MRI R2* and T2 mapping changes were associated with the activation and recovery of function in lumbar paraspinal muscles after back extension exercise, and that BOLD MRI $\mathrm{R} 2 *$ and T2 mapping may be potential tools for assessing the effectiveness of exercise prescriptions. Our findings suggest that BOLD MRI R2* mapping and T2 mapping can be used to evaluate the effectiveness of back extension exercises based on the physiological blood oxygenation level in paraspinal muscles; thus, they may aid in the timely and effective modification of exercise therapies for healthy individuals, patients with lower back pain, and people who want to get fit or lose fat. 
A

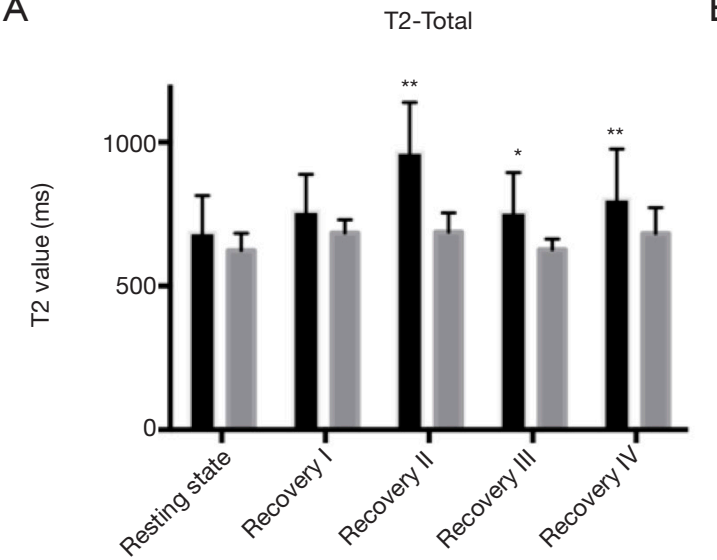

C

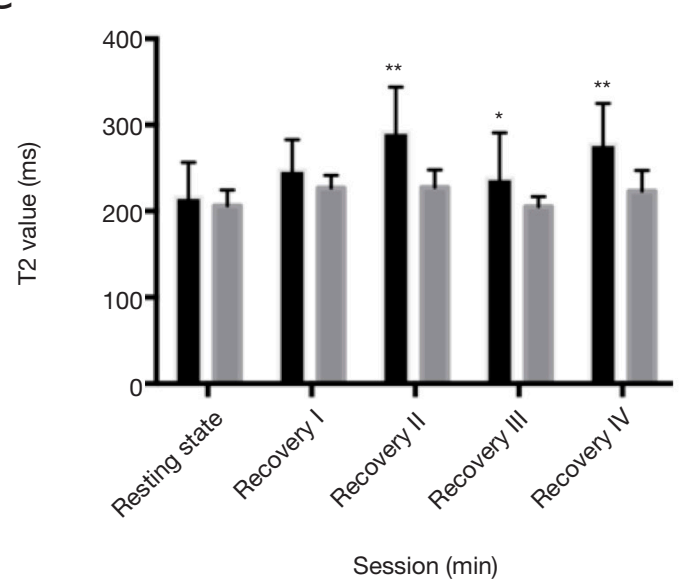

B

T2-lliocostalis

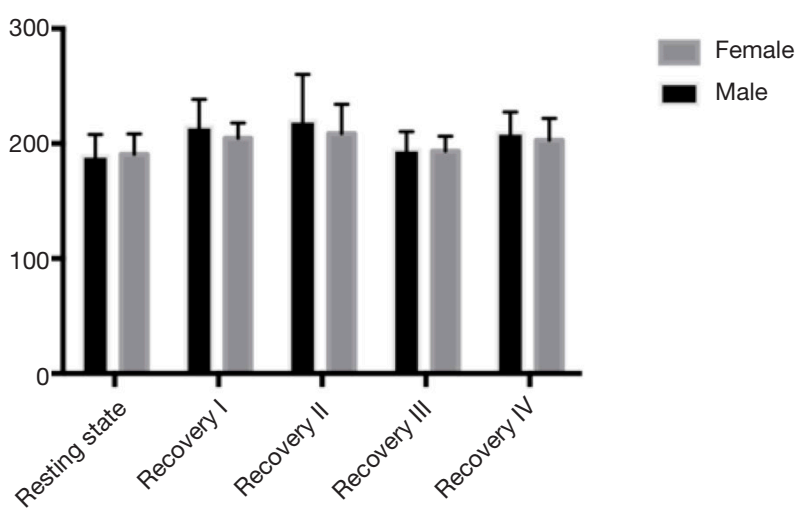

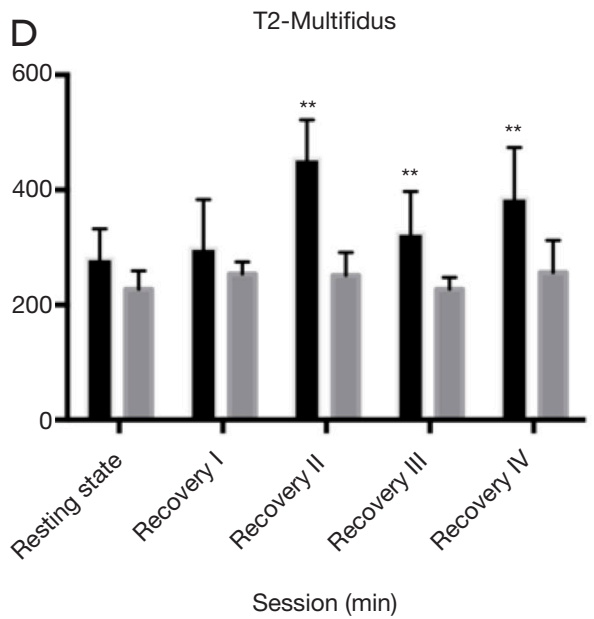

Figure 8 Sex differences in T2 values of the 3 paraspinal muscles between resting state and recovery sessions (A) The total value of 3 muscles; (B) iliocostalis; (C) longissimus; and (D) multifidus. ${ }^{*} \mathrm{P}<0.05,{ }^{* *} \mathrm{P}<0.01$.

\section{Acknowledgments}

Funding: This study was supported by grants from the Applied Basic Research Project of Yunnan (No. 202001AY070001-038 and 202001AY070001-200), and the Science Research Fund Project in the Department of Education of Yunnan Province (No. 2019J1245).

\section{Footnote}

Reporting Checklist: The authors have completed the MDAR reporting checklist. Available at http://dx.doi.org/10.21037/ atm-21-279

Data Sharing Statement: Available at http://dx.doi. org/10.21037/atm-21-279
Conflicts of Interest: All authors have completed the ICMJE uniform disclosure form (available at http://dx.doi. org/10.21037/atm-21-279). The authors have no conflicts of interest to declare.

Ethical Statement: The authors are accountable for all aspects of the work in ensuring that questions related to the accuracy or integrity of any part of the work are appropriately investigated and resolved. This prospective study was approved and carried out in accordance with the ethical standards set up by institutional committee of the First Affiliated Hospital of Kunming Medical University. Written informed consent was obtained from every participant. This study was conducted in accordance with the Declaration of Helsinki (as revised in 2013). 
Open Access Statement: This is an Open Access article distributed in accordance with the Creative Commons Attribution-NonCommercial-NoDerivs 4.0 International License (CC BY-NC-ND 4.0), which permits the noncommercial replication and distribution of the article with the strict proviso that no changes or edits are made and the original work is properly cited (including links to both the formal publication through the relevant DOI and the license). See: https://creativecommons.org/licenses/by-nc-nd/4.0/.

\section{References}

1. Feigenbaum MS, Pollock ML. Prescription of resistance training for health and disease. Med Sci Sports Exerc 1999;31:38-45.

2. Mereles D, Ehlken N, Kreuscher S, et al. Exercise and respiratory training improve exercise capacity and quality of life in patients with severe chronic pulmonary hypertension. Circulation 2006;114:1482-9.

3. Vissing CR, Hedermann G, Vissing J. Moderate-intensity aerobic exercise improves physical fitness in bethlem myopathy. Muscle Nerve 2019;60:183-8.

4. Ciolac EG, Rodrigues-da-Silva JM. Resistance Training as a Tool for Preventing and Treating Musculoskeletal Disorders. Sports Med 2016;46:1239-48.

5. Verbrugghe J, Agten A, Stevens S, et al. Exercise Intensity Matters in Chronic Nonspecific Low Back Pain Rehabilitation. Med Sci Sports Exerc 2019;51:2434-42.

6. Verbrugghe J, Knippenberg E, Palmaers S, et al. Motion detection supported exercise therapy in musculoskeletal disorders: a systematic review. Eur J Phys Rehabil Med 2018;54:591-604.

7. Ramírez-Vélez R, Izquierdo M. Editorial: Precision Physical Activity and Exercise Prescriptions for Disease Prevention: The Effect of Interindividual Variability Under Different Training Approaches. Front Physiol 2019; 10:646.

8. Egger F, Meyer T, Hecksteden A. Interindividual Variation in the Relationship of Different Intensity Markers-A Challenge for Targeted Training Prescriptions. PLoS One 2016;11:e0165010.

9. Paolucci T, Attanasi C, Cecchini W, et al. Chronic low back pain and postural rehabilitation exercise: a literature review. J Pain Res 2018;12:95-107.

10. Hansen D, Niebauer J, Cornelissen V, et al. Exercise Prescription in Patients with Different Combinations of Cardiovascular Disease Risk Factors: A Consensus Statement from the EXPERT Working Group. Sports
Med 2018;48:1781-97.

11. Quittner M, Rantalainen T, Ridgers ND, et al. Intervertebral disc status is associated with vertebral marrow adipose tissue and muscular endurance. Eur Spine J 2018;27:1704-11.

12. Watanabe M, Cheng K, Murayama Y, et al. Attention but not awareness modulates the BOLD signal in the human V1 during binocular suppression. Science 2011;334:829-31.

13. Ogawa S, Lee TM, Kay AR, et al. Brain magnetic resonance imaging with contrast dependent on blood oxygenation. Proc Natl Acad Sci U S A 1990;87:9868-72.

14. Partovi S, Schulte AC, Jacobi B, et al. Blood oxygenation level-dependent (BOLD) MRI of human skeletal muscle at 1.5 and 3 T. J Magn Reson Imaging 2012;35:1227-32.

15. Ledermann HP, Heidecker HG, Schulte AC, et al. Calf muscles imaged at BOLD MR: correlation with TcPO2 and flowmetry measurements during ischemia and reactive hyperemia--initial experience. Radiology 2006;241:477-84.

16. Matsuki K, Watanabe A, Ochiai S, et al. Quantitative evaluation of fatty degeneration of the supraspinatus and infraspinatus muscles using T2 mapping. J Shoulder Elbow Surg 2014;23:636-41.

17. Ledermann HP, Schulte AC, Heidecker HG, et al. Blood oxygenation level-dependent magnetic resonance imaging of the skeletal muscle in patients with peripheral arterial occlusive disease. Circulation 2006;113:2929-35.

18. Manka R, Paetsch I, Schnackenburg B, et al. BOLD cardiovascular magnetic resonance at 3.0 tesla in myocardial ischemia. J Cardiovasc Magn Reson 2010;12:54.

19. Glaser C. New techniques for cartilage imaging: T2 relaxation time and diffusion-weighted MR imaging. Radiol Clin North Am 2005;43:641-53, vii.

20. Kim HK, Laor T, Horn PS, et al. T2 mapping in Duchenne muscular dystrophy: distribution of disease activity and correlation with clinical assessments. Radiology 2010;255:899-908.

21. Shi HJ, Li YF, Ji WJ, et al. Evaluation of Visceral Adipose Tissue Oxygenation by Blood Oxygen Level-Dependent MRI in Zucker Diabetic Fatty Rats. Obesity 2018;26:1017-25.

22. Mayer J, Mooney V, Dagenais S. Evidence-informed management of chronic low back pain with lumbar extensor strengthening exercises. Spine J 2008;8:96-113.

23. Muller MD, Li Z, Sica CT, et al. Muscle oxygenation during dynamic plantar flexion exercise: combining BOLD MRI with traditional physiological measurements. Physiol Rep 2016;4:e13004.

24. Bane O, Besa C, Wagner M, et al. Feasibility and 
reproducibility of BOLD and TOLD measurements in the liver with oxygen and carbogen gas challenge in healthy volunteers and patients with hepatocellular carcinoma. J Magn Reson Imaging 2016;43:866-76.

25. Stacy MR, Qiu M, Papademetris X, et al. Application of BOLD Magnetic Resonance Imaging for Evaluating Regional Volumetric Foot Tissue Oxygenation: A Feasibility Study in Healthy Volunteers. Eur J Vasc Endovasc Surg 2016;51:743-9.

26. Saltin B, Radegran G, Koskolou MD, et al. Skeletal muscle blood flow in humans and its regulation during exercise. Acta Physiol Scand 1998;162:421-36.

27. Jordan BF, Kimpalou JZ, Beghein N, et al. Contribution of Oxygenation to BOLD Contrast in Exercising Muscle. Magn Reson Med 2004;52:391-6.

28. Bahr R. Excess postexercise oxygen consumption-magnitude, mechanisms and practical implications. Acta Physiol Scand Suppl 1992;605:1-70.

29. Batrakoulis A, Jamurtas AZ, Georgakouli K, et al. High intensity, circuit-type integrated neuromuscular training alters energy balance and reduces body mass and fat in obese women: A 10-month training-detraining randomized controlled trial. PloS One 2018;13:e0202390.

30. Corbianco S, Cavallini G, Baldereschi G, et al. Whole body vibration and treadmill training in Parkinson's disease rehabilitation: effects on energy cost and recovery phases. Neurol Sci 2018;39:2159-68.

31. Luszczyk M, Flis DJ, Szadejko I, et al. Excess postexercise oxygen consumption and fat oxidation in recreationally trained men following exercise of equal energy expenditure: comparisons of spinning and constant endurance exercise. J Sports Med Phys Fitness 2018;58:1781-9.

32. Malatesta D, Werlen C, Bulfaro S, et al. Effect of highintensity interval exercise on lipid oxidation during

Cite this article as: Huang Y, Wei J, Han D, Jiang Y, Zhang J, Zhang Z, He B. Muscular blood oxygen level-dependent MRI is beneficial to evaluate effectiveness of an exercise prescription. Ann Transl Med 2021;9(6):470. doi: 10.21037/atm-21-279 postexercise recovery. Med Sci Sports Exerc 2009;41:364-74.

33. Larsen I, Welde B, Martins C, et al. High- and moderateintensity aerobic exercise and excess post-exercise oxygen consumption in men with metabolic syndrome. Scand J Med Sci Sports 2014;24:e174-9.

34. Gaesser GA, Brooks GA. Metabolic bases of excess postexercise oxygen consumption: a review. Med Sci Sports Exerc 1984;16:29-43.

35. Yuan F, Guo ZZ, Ji WJ, et al. BOLD-MRI evaluation of subcutaneous and visceral adipose tissue oxygenation status: effect of dietary salt intake. Am J Transl Res 2015;7:598-606.

36. Bajwa A, Wesolowski R, Patel A, et al. Blood oxygenation level-dependent cmr- derived measures in critical limb ischemia and changes with revascularization. J Am Coll Cardiol 2016;67:420-31.

37. Schewzow K, Fiedler GB, Meyerspeer M, et al. Dynamic ASL and T2-weighted MRI in exercising calf muscle at 7 T: a feasibility study. Magn Reson Med 2015;73:1190-5.

38. Mayer JM, Graves JE, Clark BC, et al. The use of magnetic resonance imaging to evaluate lumbar muscle activity during trunk extension exercise at varying intensities. Spine 2005;30:2556-63.

39. Mukaimoto T, Semba S, Inoue Y, et al. Changes in transverse relaxation time of quadriceps femoris muscles after active recovery exercises with different intensities. J Sports Sci 2014;32:766-75.

40. Smith J, Mc Naughton L. The effects of intensity of exercise on excess postexercise oxygen consumption and energy expenditure in moderately trained men and women. Eur J Appl Physiol Occup Physiol 1993;67:420-5.

(English Language Editor: J. Reynolds) 